\title{
FACULTY READINESS FOR DIGITAL LEARNING ENVIRONMENTS: A RESEARCH ON ONLINE ATTENDANCE MANAGEMENT SYSTEMS
}

\author{
DOI: 10.17261/Pressacademia.2019.1057 \\ PAP- V.9-2019(4)-p.14-19
}

Mehmet Oytun Cibaroglu' ${ }^{1}$, Naciye Guliz Ugur ${ }^{2}$, Aykut Hamit Turan ${ }^{3}$

${ }^{1}$ Bursa Technical University, Department of Information Technologies, Bursa, Turkey oytun.cibaroglu@btu.edu.tr, ORCID: 0000-0002-5763-0770

${ }^{2}$ Sakarya University, Department of Management Information Systems, Sakarya, Turkey ngugur@sakarya.edu.tr, ORCID: 0000-0003-2364-5445

${ }^{3}$ Sakarya University, Department of Management Information Systems, Sakarya, Turkey ahturan@sakarya.edu.tr, ORCID: 0000-0002-8855-4643

\section{To cite this document}

Cibaroglu, M.O., Ugur, N.G., Turan, A.H., (2019). Faculty readiness for digital learning environments: a research on online attendance management systems. PressAcademia Procedia (PAP), V.9, p.14-19

Permemant link to this document: http://doi.org/10.17261/Pressacademia.2019.1057

Copyright: Published by PressAcademia and limited licenced re-use rights only.

\begin{abstract}
Purpose- The purpose of this study is to investigate the readiness of the faculty towards digital learning management tools. Online attendance management systems are investigated as a part of the digitalized education environment. The statistical relations among technology readiness factors and technology acceptance variables are investigated.

Methodology- The study adopted a quantitative research method, and the survey is used as the data gathering tool. The survey consisted of items from the Technology Readiness Index (TRI) and Technology Acceptance Model (TAM). Across Turkey, 317 faculty from seven universities participated in the final survey.

Findings- The analysis reveals that there is a statistically significant yet weak relationship among technology readiness variables and acceptance of online attendance management systems. In addition, descriptive statistics presents some valuable insight regarding technology readiness situation of the faculty members.

Conclusion- Education environments are enhanced with technological tools and supported with online platforms. The most critical point is that the usage of these technological advancements is limited by technology acceptance, and this study reveals that technology readiness is a key component of technology acceptance.
\end{abstract}

Keywords: Technology readiness, technology acceptance, educational technology, online attendance system, faculty members JEL Codes: O33, 123, L86

\section{INTRODUCTION}

Information technologies, which affect a wide range of aspects of life, ranging from space research to online shopping, economics to scientific software, are also widely employed in the education sector. An application used in education is called online attendance management system. It is developed for students' daily participation (or non-continuance) in any courses in educational institutions. This system is mostly generated as a module in student information system software. It can be managed from a web interface. The system also helps in reporting and assessing student eligibility. It does not only enhance work efficiency but also provides a study and development environment for the students.

In Turkey, the online attendance management systems are generally used as a part of web-based academic information systems; a recent tendency has emerged to use attendance system for managing lecture attendance. This study aims to provide answers whether the online attendance system is adopted by using both Technology Readiness Index (TRI) developed by Parasaruman (2000) and Davis's (1989) Technology Acceptance Model (TAM). 
In the context of this phenomenon, this study aims to provide the structural and socio-psychometric criteria for both of the two theories. It is also a preliminary study aiming to provide descriptive statistics of the research.

\section{LITERATURE REVIEW}

In the literature, there are many studies about creation of students absence and attendance system that some of which includes mobile-based attendance system, fingerprint based attendance system, iris-based attendance system, face recognition based attendance system, RFID (Radio Frequency Identification) based attendance system, Bluetooth based attendance system, NFC (Near Field Communication) based attendance system (Patel and Priya, 2014; Jacksi, 2015; Jacksi, Ibrahim and Zebari, 2018; Bhudke, Bhutekar, Horambe and Naik, 2016). Besides these technical studies, there are also some studies in the context of online attendance system adoption in the literature as well. While some of these studies use TRI and Tam combination to measure adoption of mandatory web-based attendance system (Nughoro and Fajar, 2017), some define requirements for integrated attendance monitoring system (Nwokeji, Olagunju, Apoorva, Frezza and Tang, 2017).

\section{DATA AND METHODOLOGY}

The study adopted a quantitative research method, and the survey is used as the data-gathering tool. The survey consisted of 10 demographic indicators and 29 items from the Technology Readiness Index (TRI) and Technology Acceptance Model (TAM). Across Turkey, 317 faculty and vocational school members from seven universities ( 6 state university and 1 private) have participated in the study. Six of the universities are located in the western part of Turkey, and the one is from the northeast part of the country. TRI was modified from Parasuraman's study (2000), and TAM components (perceived of usefulness, perceived ease of use, and behavior intention) was modified from Davis (1989).

In the study, 5-point Likert scales were used from the range of 1-Strongly Agree to 5-Strongly Disagree. A number of respondents based on gender consisted of $175(55,2 \%)$ male and $142(44,8 \%)$ female. According to descriptive analysis, the study has five age ranges that consist of $20-30,31-40,41-50,51-60$, and $60+.70$ respondents $(22,1 \%)$ belong to $20-30$ age range; 164 respondents $(51,7 \%)$ belong to $31-40 ; 52$ respondents $(16,4 \%)$ belong to $41-50 ; 20$ respondents $(6,3 \%)$ belong to 51-60 and 11 respondents (3,5\%) belong to $60+$.

Table 1: Demographics

\begin{tabular}{|c|c|c|c|c|c|c|c|}
\hline Variables & Categories & $\mathbf{N}$ & (\%) & Variables & Catergories & $\mathbf{N}$ & (\%) \\
\hline \multirow{2}{*}{ Gender } & Male & 175 & 55,2 & \multirow{5}{*}{ Usage of IT Apps (Hours) } & 1-2 per Week & 37 & 11,6 \\
\hline & Female & 142 & 44,8 & & 3-4 per Week & 57 & 18,0 \\
\hline \multirow{5}{*}{ Age } & $20-30$ & 70 & 22,1 & & 1-2 per Day & 88 & 27,8 \\
\hline & $31-40$ & 164 & 51,7 & & 3-4 per Day & 57 & 18,0 \\
\hline & $41-50$ & 52 & 16,4 & & 4+ per Day & 78 & 24,6 \\
\hline & $51-60$ & 20 & 6,3 & \multirow{4}{*}{ IT Usage Level } & Very Few & 11 & 3,5 \\
\hline & $60+$ & 11 & 3,5 & & Enough & 117 & 36,9 \\
\hline \multirow{5}{*}{ Title } & Instructor & 82 & 25,9 & & Good & 136 & 42,9 \\
\hline & Research Assistant & 109 & 34,4 & & Very Good & 53 & 16,7 \\
\hline & Assistant Professor & 84 & 26,5 & \multirow{5}{*}{ Using OAS Since When } & Less Than 1 Month & 92 & 29,0 \\
\hline & Associate Professor & 22 & 6,9 & & Between 1-3 Months & 23 & 7,3 \\
\hline & Professor & 20 & 6,3 & & Between 4-6 Months & 15 & 4,7 \\
\hline \multirow{3}{*}{ Graduation } & Bachelor & 17 & 5,4 & & Between 7-12 Months & 34 & 10,7 \\
\hline & Master & 92 & 29,0 & & Longer Than 1 Year & 153 & 48,3 \\
\hline & Doctor of Philosophy & 208 & 65,6 & \multirow{7}{*}{ Usage of OAS Level } & Very Few & 167 & 52,7 \\
\hline \multirow{6}{*}{ Experience } & $0-3$ Years & 61 & 19,2 & & Once a Week & 46 & 14,5 \\
\hline & 4-6 Years & 57 & 18,0 & & Several a Week & 72 & 22,7 \\
\hline & 7-9 Years & 75 & 23,7 & & Once a Day & 6 & 1,9 \\
\hline & $10-12$ Years & 33 & 10,4 & & \multirow{2}{*}{ Several a Day } & \multirow{2}{*}{26} & \multirow{2}{*}{8,2} \\
\hline & $13+$ Years & 91 & 28,7 & & & & \\
\hline & Total & 317 & 100 & & Total & 317 & 100 \\
\hline
\end{tabular}


As seen in Table 1, 109 respondents are research assistants (\%34,4). 208 participants have a Ph.D. degree (\%65,6). 91 participants have $13+$ years' work experience $(\% 28,7)$. It can be observed that also, 78 participants use IT applications most (4+ hours per day). 136 participants (\%42,9) are good at using IT components. It seems that 153 participants $(\% 48,3)$ are using the online attendance system for 1+ year. On the contrast, even 153 participants use online attendance system for 1+ year, only 26 of them $(\% 8,2)$ are using it several times per day. 167 of them $(\% 52,7)$ use it very few. This indicator indicates that the online attendance system does not be used frequently, and participants started to use systems quite recently.

\section{FINDINGS}

In this study, descriptive statistics (as above), inter-correlations, independent samples T-test, and One-Way ANOVA tests were used to examine if there were differences in between TRI and TAM variables among defined groups. Below the tables, we explained some interrelationships among variables.

Table 2: TRI and TAM Variables Descriptive

\begin{tabular}{|l|c|c|}
\hline TRI Variables & Mean & Std. Deviation \\
\hline Optimism & 1,813 &, 511 \\
\hline Innovativeness & 2,067 &, 638 \\
\hline Discomfort & 2,649 &, 749 \\
\hline Insecurity & 2,138 &, 681 \\
\hline TRI & 2,166 &, 644 \\
\hline TAM Variables & &, 857 \\
\hline Perceived Usefulness & 2,106 &, 735 \\
\hline Perceived Ease of Use & 2,037 &, 872 \\
\hline Behavioural Intention & 2,305 &, 821 \\
\hline TAM & 2,149 & \\
\hline
\end{tabular}

In Table 2, there are presented both TRI and TAM variables in addition to overall TRI and TAM means and standard deviations.

Table 3: Variables Inter-Correlations

\begin{tabular}{|c|c|c|c|c|c|c|c|c|}
\hline & & OPT & INN & DIS & INS & PU & PEOU & INT \\
\hline \multirow{2}{*}{ Optimism } & Pearson Correlation & 1 & ,696** &,- 011 & 025 & $425 * *$ & $479 * *$ &, $385^{* *}$ \\
\hline & Sig. (2-tailed) & & ,000 & 841 & 662 & ,000 & ,000 & ,000 \\
\hline \multirow{2}{*}{ Innovatiness } & Pearson Correlation & ,696** & 1 & ,042 &,- 048 & ,334** & ,422** & ,336** \\
\hline & Sig. (2-tailed) & ,000 & & ,461 & 398 & ,000 & ,000 &, 000 \\
\hline \multirow{2}{*}{ Discomfort } & Pearson Correlation &,- 011 & 042 & 1 & ,402** & 081 & ,027 &, $128 *$ \\
\hline & Sig. (2-tailed) & 841 & ,461 & & ,000 & 150 & ,636 & 022 \\
\hline \multirow{2}{*}{ Insecurity } & Pearson Correlation & 025 &,- 048 &, $402 * *$ & 1 & ,140* & ,054 & 110 \\
\hline & Sig. (2-tailed) & ,662 & ,398 & ,000 & & ,013 & ,336 & 051 \\
\hline \multirow{2}{*}{ Perceived Usefulness } & Pearson Correlation & ,425** & $334 * *$ & 081 & ,140* & 1 & ,493** & ,769** \\
\hline & Sig. (2-tailed) &, 000 &, 000 & 150 & 013 & &, 000 &, 000 \\
\hline \multirow{2}{*}{ Perceived Ease of Use } & Pearson Correlation & ,479** & ,422** & 027 & ,054 &, $493 * *$ & 1 &, $443^{* *}$ \\
\hline & Sig. (2-tailed) &, 000 &, 000 & ,636 & ,336 &, 000 & & ,000 \\
\hline \multirow{2}{*}{ Behavioural Intention } & Pearson Correlation & ,385** & $336 * *$ & ,128* & 110 & ,769** & $443 * *$ & 1 \\
\hline & Sig. (2-tailed) &, 000 & ,000 & 022 & 051 &, 000 & ,000 & \\
\hline
\end{tabular}

${ }^{* *}$ Correlation is significant at the 0.01 level (2-tailed).

*Correlation is significant at the 0.05 level (2-tailed).

In Table 3, the Pearson correlation test has been used to test the inter-correlation for the main variables. It can be easily seen that most variables are inter-correlated positively between them, but optimism \& discomfort and innovativeness \& insecurity variables are negatively correlated. 
Table 4: Gender T-test Results

\begin{tabular}{|l|c|c|c|c|c|}
\hline TRI Variables & $\begin{array}{c}\text { Levene's Test for } \\
\text { Equality of } \\
\text { Variances (F/Sig.) }\end{array}$ & Male (Mean) & Female (Mean) & t Value & Sig. (2-tailed) \\
\hline Optimism & $2,793 / 0,96$ & 1,807 & 1,812 &,- 252 &, 801 \\
\hline Innovativeness &, $493 /, 483$ & 1,997 & 2,153 & $-2,172$ &, 031 \\
\hline Discomfort &, $353 /, 553$ & 2,567 & 2,751 & $-2,180$ &, 030 \\
\hline Insecurity &, $017 /, 895$ & 2,124 & 2,154 &,- 398 &, 691 \\
\hline TAM Variables & & & & &, 767 \\
\hline Perceived Usefulness &, $652 /, 420$ & 2,093 & 2,122 &,- 296 &, 310 \\
\hline Perceived Ease of Use &, $385 /, 535$ & 2,000 & 2,084 & $-1,017$ &, 683 \\
\hline Behavioural Intention &, $859 /, 355$ & 2,287 & 2,327 &,- 408 & \\
\hline
\end{tabular}

As can be seen from Table 4, all variables distributed homogeneously, and there are no statistically significant relationships between gender and TAM/TRI variables.

Table 5: IT Usage Level One-Way ANOVA

\begin{tabular}{|l|c|c|c|c|}
\hline \multirow{2}{*}{ IT Usage Levels } & TRI Variables & $\begin{array}{c}\text { Test of Homogeneity of } \\
\text { Variances (Sig.) }\end{array}$ & F & Sig. \\
\hline \multirow{2}{*}{ Very Few } & Optimism &, 725 & 9,673 &, 000 \\
\hline \multirow{2}{*}{ Enough } & Innovatiness &, 080 & 17,699 &, 000 \\
\cline { 2 - 5 } & Discomfort &, 026 &, 825 &, 481 \\
\cline { 2 - 5 } & Insecurity &, 419 & 1,868 &, 135 \\
\hline \multirow{2}{*}{ Veod } & TAM Variables & & &, 131 \\
\cline { 2 - 5 } & Perceived Usefulness &, 005 & 1,891 &, 000 \\
\cline { 2 - 5 } & Perceived Ease of Use &, 595 & 7,737 &, 057 \\
\cline { 2 - 5 }
\end{tabular}

As can be seen from Table 5, all TRI variables and TAM variable Perceived Ease of Use are distributed homogeneously $(p>0,05)$. However, Perceived Usefulness and Behavioural Intention variables do not have homogenous distribution. There is a significant correlation in the group of IT usage level for Optimism, Innovativeness, and Perceived Ease of Use. In order to understand which IT usage level groups differ significantly, the Post-Hoc test is examined for each group. For the two variables of TRI (Optimism and Innovativeness), the Tukey test is run due to homogeneous distribution. For the TAM variable (Perceived Ease of Use), the Games-Howell test is performed due to unequal variances.

\section{Table 6: IT Usage Level Post Hoc}

\begin{tabular}{|c|c|c|c|c|c|}
\hline Dependent Variables & Test Type & (I) IT Usage Level & (J) IT Usage Level & Mean Difference (I-J) & Sig. \\
\hline \multirow{2}{*}{ Optimisim } & \multirow{2}{*}{ Tukey } & \multirow{2}{*}{ Enough } & Good &, $21215^{*}$ & ,004 \\
\hline & & & Very Good & ,37724* & 000 \\
\hline \multirow{3}{*}{ Innovativeness } & \multirow{3}{*}{ Tukey } & Very Few & Very Good & ,89503* & ,000 \\
\hline & & \multirow{2}{*}{ Enough } & Good &, $34005^{*}$ & 000 \\
\hline & & & Very Good & $62090^{*}$ & 000 \\
\hline Perceived Ease of Use & Games-Howell & Enough & Very Good & $44079^{*}$ & 001 \\
\hline
\end{tabular}

*The variables Discomfort, Insecurity, Perceived Ease of Use, and Behavioural Intention have no significant mean differences.

According to Table 6, individuals with enough IT usage level tend to be more optimistic than individuals with good and very good IT usage level. People who have very few IT usage level are also more innovative than people with very good IT usage level. People who have enough IT usage level also tend to be more innovative than people with good and very good IT usage level. In addition, people who have enough IT usage level experience more PEoU than people who have a very good IT usage level.

Users' optimism seems to be decreasing with their experience. They may see that they can't find what they look for. The individuals who use the OAS very few, their innovation levels seem to be more than expert users. The people who use the OAS very few take less risk and name themselves as innovative. On the use of new technologies, likewise, the more 
experienced usage of OAS cause less useful expectation. They may be confused with finding OAS useful, or if the usage of OAS did not reach enough expectation levels, the survey might have been answered with a disappointment.

Table 7: OAS Usage Level One-Way ANOVA

\begin{tabular}{|l|c|c|c|c|}
\hline \multirow{2}{*}{ OAS Usage Level } & TRI Variables & $\begin{array}{c}\text { Test of Homogeneity of } \\
\text { Variances (Sig.) }\end{array}$ & F & Sig. \\
\hline \multirow{2}{*}{ Very Few } & Optimism &, 334 & 2,197 &, 069 \\
\hline & Innovatiness &, 090 & 3,002 &, 019 \\
\hline Once a Week & Discomfort &, 128 & 2,758 &, 028 \\
\hline \multirow{2}{*}{ Several a Week } & Insecurity &, 063 &, 723 &, 577 \\
\cline { 2 - 5 } & TAM Variables & & &, 000 \\
\hline Once a Day & Perceived Usefulness &, 003 & 10,272 &, 001 \\
\hline \multirow{2}{*}{ Several a Day } & Perceived Ease of Use &, 419 & 4,769 &, 000 \\
\cline { 2 - 5 } & Behavioural Intention &, 000 & 11,663 & \\
\hline
\end{tabular}

As can be seen from Table 7, all TRI variables are distributed homogeneously $(p>0,05)$. However, Perceived Usefulness and Behavioural Intention variables do not have homogenous distribution. On the other hand, Perceived Ease of Use variable has homogenous distribution. As ANOVA results present, there is no significant correlation between OAS usage level and TRI variables. However, there are significant relationship and differences between OAS usage level and TAM variables. The PostHoc tests are examined for each group, in order to understand which OAS usage level groups differ according to the variables. For the two variables of TAM (PU and $\mathrm{BI}$ ), the Tukey test is performed due to homogeneous distribution. For other TAM variable Perceived Ease of Use, the Games-Howell test is performed due to variances, not equal distribution.

Table 8: OAS Usage Level Post Hoc

\begin{tabular}{|c|c|c|c|c|c|}
\hline Dependent Variables & Test Type & (I) OAS Usage Level & (J) OAS Usage Level & Mean Difference (I-J) & Sig. \\
\hline \multirow{2}{*}{ Perceived Usefulness } & \multirow{2}{*}{ Games-Howell } & \multirow{2}{*}{ Very Few } & Once a Week &, $63486^{*}$ & ,000 \\
\hline & & & Several a Week &, $57105^{*}$ & ,000 \\
\hline Perceived Ease of Use & Tukey & Very Few & Once a Week & ,42224* & ,001 \\
\hline \multirow{2}{*}{ Behavioral Intention } & \multirow{2}{*}{ Games Howell } & \multirow{2}{*}{ Very Few } & Once a Week &, $56375^{*}$ & ,001 \\
\hline & & & Several a Week & $65735^{*}$ & , 000 \\
\hline
\end{tabular}

*The variables Optimism, Innovativeness, Discomfort, and Insecurity have no significant mean differences.

According to Table 8, those who have very few OAS usage level differ significantly in the context of perceived usefulness from those with once and several in a week OAS usage. In addition, individuals who have very few OAS usage level have more feeling of ease of use and those who have very few OAS usage level, have more intention to use OAS than once and several a week OAS usage.

It seems that as the number of usage increases, perceived usefulness increases, too, since users appreciate the value of the software more. That's why people find the software easier to use as they are more involved in it. They gain experience and intend to use them as they enhance their experience. They are also more satisfied with the software, and they understand the value of it.

\section{CONCLUSION}

Education environments are enhanced with technological tools and supported by online platforms. The most critical point is that the usage of these technological advancements is limited by technology acceptance, and this study reveals that technology readiness is a key component of technology acceptance. This study explains the TAM model using technology readiness constructs for online attendance system. In addition, descriptive statistics present a valuable insight regarding technology readiness situation of users. Unexpectedly, the descriptive data of the online attendance system shows that there is a weak relationship between IT usage level and OAS usage frequency. In addition, there is no significant relationship between gender and TAM/TRI variables. This result indicates that OAS cannot be adopted in the circle of good and very good IT applications users. However, the strong IT usage level should have supported the use \& adoption of OAS in the context of technology readiness. On the other hand, it is seen that individuals with enough IT usage level tend to be more optimistic than individuals with good and very good IT usage level. Individuals who have very few OAS usage level differ significantly in the context of perceived usefulness from users with once and several in a week of OAS usage. We can say that both IT and 
OAS usage level might be affected by some TRI and TAM variables as especially optimism and innovativeness; perceived ease of use, perceived usefulness, and behavioral intention.

\section{REFERENCES}

Bhudke, P.A., Bhutekar, R.S., Horambe, V.V., and Naik, S. (2016). "VIVA-Tech SAM: Student Attendance Management System". International Journal of Computer Applications Proceedings on National Conference on Role of Engineers in National Building 6(1): 10-14.

Davis, F.D. (1989). “Perceived Usefulness, Perceived Ease of Use, And User Acceptance”. MIS Quarterly. 13(3): 319-340.

Fabrigar, L.R., Wegener, D.T., MacCallum, R.C. and Strahan, E.J. (1999). “Evaluating the Use of Exploratory Factor Analysis in Psychological Research". Psychological Methods. 4(3): 272-299.

Field, A. (2009). Discovering Statistics Using SPSS 3rd ed. Thousand Oaks, California: SAGE Pub.

Finney, J. (1970). Time and again. New York, NY: Simon and Schuster.

Hair, J.F., Black, W.C., Babin, B.J. and Anderson, R.E. (2010). Multivariate Data Analysis Seventh Edition. Essex: Prentice Hall.

Jacksi K. (2015). Design and Implementation of Online Submission and Peer Review System: A Case Study of E-Journal Of University Of Zakho. International Journal of Scientific \& Technology Research, 4(8): 83-85.

Jacksi, K., Ibrahim, F. and Zebari, S. (2018). Student Attendance Management System. Scholars Journal of Engineering and Technology, 6(2): 49-53.

Ming-Ling Lai, (2008). Technology Readiness, Internet Self-Efficacy and Computing Experience of Professional Accounting Students. CampusWide Information Systems, 25(1): 18-29.

Norusis, M. J. (1993). SPSS for Windows: Professional Statics, Release 6.0, Chicago: SPSS Inc.

Nughoro, M.A and Fajar, M.A. (2017). Effects of Technology Readiness Towards Acceptance of Mandatory Web-Based Attendance System. Procedia Computer Science, 124: 319-328.

Nunnally, J. C. (1978). Psychometric Theory (2nd ed.), New York: McGraw-Hill.

Nwokeji, J.C., Olagunju, A., Apoorva, A., Frezza, S. and Tang, M.M. (2017). Requirements Model for an Integrated Attendance Monitoring System (IAMS). Future Technologies Conference (FTC), 29-30 November 2017, Vancouver, Canada.

Parasuraman, A. (2000). Technology Readiness Index (TRI): A Multiple-Item Scale to Measure Readiness to Embrace New Technologies. Journal of Service Research, 2(4): 307-320.

Patel, U.A. and Priya, S. R. (2014). Development of A Student Attendance Management System Using RFID and Face Recognition: A Review. International Journal of Advance Research inComputer Science and Management Studies, 2(8): 109-119.

Pires, P.J., Filho, B.A.C. and Cunha, J.C. (2011). Technology Readiness Index (TRI) Factors as Differentiating Elements between Users and Non Users of Internet Banking, and as Antecedents of the Technology Acceptance Model (TAM). in ENTERprise Information Systems International Conference Proceedings, Part II, CENTERIS 2011, Vilamoura, Portugal, October 5-7, 2011, pp. 215-229.

Taherdoost, H., Sahibuddin, S. and Jalaliyoon, N. (2014). Exploratory Factor Analysis; Concepts and Theory. Advances in Applied and Pure Mathematics, pp. 375-382

Yong, A.G. and Pearce, S. (2013). A Beginner's Guide to Factor Analysis: Focusing on Exploratory Factor Analysis. Tutorials in Quantitative Methods for Psychology, 9(2): 79-94. 